\title{
Updating Homeostasis
}

\section{Walter M Bortz}

Stanford University, School of Medicine, Portola Valley, CA 94028, United States

"Corresponding author: Walter M Bortz, Clinical Professor of Medicine, Stanford University, School of, Medicine,167 Bolivar Lane, Portola Valley, CA 94028, United States, Tel: (650) 854-2273, E-mail: drwbortz@gmail.com

Received date: Jan 03, 2015; Accepted date: Jul 29, 2015; Published date: Aug 6, 2015

Copyright: (c) 2015 Bortz WM. This is an open-access article distributed under the terms of the Creative Commons Attribution License, which permits unrestricted use, distribution, and reproduction in any medium, provided the original author and source are credited.

\section{Commentary}

One century ago, Walter Cannon coined the term "homeostasis" to capture the remarkable stability exhibited by living creatures [1]. His work extended Claude Bernard's intuition about the myriad mechanisms that an organism possesses to permit precise adjustment to the assaults of the environment, both interior and exterior [2].

The term homeostasis has served well, but with the explosive advances in molecular biology and particularly the appearance of the epidemic of aging the term homeostasis is no longer adequate.

\section{New Term}

10 years ago, a group of us put on an international meeting at the NIH entitled "The Energetic and Dynamic Basis of Health and Aging" [3]. The centerpiece of our conference was the reification of the term homeodynamics [4]. This word was proposed and elaborated by Dr. Gene Yates of UCLA who was a leader of our conference. Homeodynamics extends homeostasis into a more inclusive term. It is evident that there is no stasis in life. All of life is dynamic. $98 \%$ of a body's atoms are replaced each year. The Krebs cycle turns over $2.66 \times 10^{\wedge} 21$ times per minute. The half-life of an intestinal cell is measured in days. Stasis is nowhere to be found. Life is a verb rather than a noun.

\section{Thermodynamics}

This effort to upgrade homeostasis is fundamentally grounded in the Second Law of Thermodynamics which describes the process of energy flow [5]. The First Law proclaims the constancy of the amount of energy, conservation. The Second Law proclaims its inevitable redistribution. The Second Law is cosmic in scope. It applies to everything in the universe, canyons, Chevrolets, daffodils, us. Entropy is everywhere apparent. Time is a by-product of the Second Law.

Erwin Schrodinger elaborated the relationship between energy flow and life "What is Life?" [6]. Ilya Prigogine, another laureate, extended Schrodinger's reach, "Order out of Chaos" [7]. He describes an organism as a "dissipative structure" poised temporarily between order and disorder, the order created and maintained by the energetic fuel of metabolism, homeodynamics. The emergence of life from an inorganic brew conjures a virtually incomprehensible complexity that is slowly unfolding. Nanotechnology equips us with insights at an atomic level, [8] but we are always reminded that "more is different" [9]. Each organizational hierarchical level displays its own emergent properties that are unique and not predictable from knowledge of the adjacent higher or lower level.

\section{Aging}

A generic definition of aging is: The effect of an energy flow on matter over time. Any definition must transcend biology, as everything in the universe ages. Yet it is within biology that immense implications arise, yet until recently aging has lacked a sturdy conceptual framework.

Hayflick: "Aging is no longer an unknown" [10]. A thermophysical foundation is invoked. Aging is entropy, [11] made manifest by a large number of catabolic physical and biochemical changes such as protein misfolding, free radical generation, DNA damage, telomere shortening, etc., all evidences of decay in homeodynamic process.

The Gray Dawn of global aging mandates appropriate supporting terminology. Clearly stasis is alien. The heterogeneity of older people implies an active agency.

\section{No Aging Gene}

Genomics has failed to illuminate aging or its co-actor, frailty. No genome-wide associated study (GWAS) has yielded central penetrance into the patho-physiology of aging or frailty.

The new approach, EWAS, environment wide association study, incorporates the interactivity of the organism with its environment within its reach [12]. Such an upgrade of explanatory terminology incorporates homeodynamics in its rubric.

Further, homeodynamics is intrinsic to phenotypic plasticity, the molding of the organism to its environment, niche construction, [13] again a critical aspect of aging. Fraga et al. reported that the gene profile of identical twins is virtually identical in youth, but diverges progressively as the environment induces variance in gene expression, [14] epigenetics, the "epicenter" of clinical medicine [15].

\section{Epigenetics}

The process of phenotypic plasticity been far under-recognized with regard to its impact on human well-being. The work of Blair particularly emphasizes how the central bio-marker of VO2 max is explicitly influenced by physical fitness [16]. A fit person of 70 has the same all-cause mortality as the unfit person of 40 , a thirty year age offset, not related to genes, or medical care but secondary to lifestyle generated homeodynamic variance.

The importance of lifestyle on human health is captured by The General Adaptation Syndrome (Allostasis) [17,18] and Hypokinetic Disease, the Disuse Syndrome $[19,20]$ in which the pathogenic mechanism involves too much or too little energetic impact confronting the organism. Such a reconceptualization of pathologic process is in accord with the basic tenets of homeodynamics. 
The emerging clinical syndrome of frailty similarly finds appropriate expression within homeodynamics [21].

With the explosive increase in our understanding of molecular biology clinical medicine seems poised to adopt a new conceptual platform based on system rather than component, on process rather than episode, on preventive rather than repair principles. The recent report of Demetrius and Driver, "Preventing Alzheimers Disease by Means of Natural Selection" [22] is but one of a cascade of novel, revolutionary strategies deriving from recognition of energy flow, homeodynamics. Medicine emerges from the structural lag [23] between acute and chronic illness. It requires appropriate framing terminology, Homeodynamics, rather than homeostasis.

\section{References}

1. Cannon W (1932) The Wisdom of the Body. WW Norton, New York.

2. Bernard C (1865) An Introduction to the Study of Experimental Medicine. Dover Books on Biology.

3. Bortz W (2002) Conference Proceedings Dynamics and Energetics of Health and Aging NIH Conference.

4. Yates FE (2008) Homeokinetics/Homeodynamics: A Physical Heuristic for Life and Complexity. Ecological Psychology 20: 148-179.

5. Atkins P (1984) The Second Law. Scientific American Books, New York NY.

6. Schrodinger E (1967) What is Life? Physical Aspects of Living Cells. Cambridge Press, Cambridge.

7. Prigogine I, Stengers I (1984) Order out of Chaos. Bantam, New York, NY.

8. Hoffman PM (2012) Life's Ratchet: How Molecular Machines Extract Order from Chaos. Basic Books, New York NY.

9. Anderson PW (1972) More is different. Science 177: 393-396.
10. Hayflick L (2007) Biological aging is no longer an unsolved problem. Ann N Y Acad Sci 1100: 1-13.

11. Bortz WM (1986) Aging as entropy. Exp Gerontol 21: 321-328.

12. Patel CJ (2013) Systematic Evaluation of Environmental and Behavioral factors Associated with All-Cause Mortality in the United States. National Health and Nutrition Examination Survey International. Journal of Epidemiology 42: 1795-1810.

13. Odding-Smee, Laland KN, Feldman KN (2003) M Niche Construction: The Neglected Process in Evolution. Princeton University Press, Princeton NJ.

14. Fraga MF, Ballestar E, Paz MF, Ropero S, Setien F, et al. (2005) Epigenetic differences arise during the lifetime of monozygotic twins. Proc Natl Acad Sci USA 102: 10604-10609.

15. Fineberg AP (2008) Epigenetics at the Epicenter of Modern Medicine. JAMA 299: 2879-83.

16. Blair SN, Kohl HW, Paffenbarger RS Jr, Clark DG, Cooper KH, et al. (1989) Physical fitness and all-cause mortality. A prospective study of healthy men and women. JAMA 262: 2395-2401.

17. Selye H (1952) The Story of the Adaptation Syndrome. Acta, Montreal.

18. McEwen BS (2000) Allostasis, allostatic load, and the aging nervous system: Role of excitatory amino acids and excitotoxicity. Neurochem Res 25: 1219-1231.

19. Kraus H, Raab W (1961) Hypokinetic Disease, Disease Caused by Lack of Exercise. Thomas, Springfield, MA.

20. Bortz WM (1984) The disuse syndrome. West J Med 141: 691-694.

21. Bortz WM (2002) A conceptual framework of frailty: A review. J Gerontol A Biol Sci Med Sci 57: M283-288.

22. Demetrius LA, Driver JA (2015) Preventing Alzheimer's disease by means of natural selection. J R Soc Interface 12: 20140919.

23. Riley MW (1984) Structural Lag: Society's Failure to Provide Meaningful Opportunity. Wiley and Sons, Oxford. 